\title{
An Analysis of the Effect of Educational Game Training on Some Physical Parameters and Social Skills of the Children with Autism Spectrum Disorders
}

\author{
Nurgül TEZCAN KARDAŞ ${ }^{1}$ œ \\ Reşat SADIK ${ }^{2}$
}

${ }^{1,2}$ Düzce University/Faculty of Sports Sciences, Turkey Email:nur_tezcan@hotmail.com

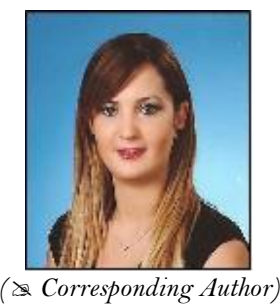

\begin{abstract}
Purpose of this research is to measure the effect of educational game training on some physical parameters and social skills of the children with Autism Spectrum Disorder. Five individuals (participants) diagnosed with Autism Spectrum Disorder participated in the research. During the research, the participants were made to play 8 different educational games for 8 weeks, and 3 days a week for 1 hour; and the sessions during the research were recorded with a video camera. Research data were obtained before and after the 8-week educational game program by using flamingo test, vertical jump test, plate tapping test, sit and reach test, and by performance determination form for individuals with pervasive developmental disability. SPSS 25 package program was used in the analysis of the data. The Wilcoxon test, a nonparametric test, was used to evaluate pre- and post-test results. As a result of the study, it was found that the educational games have positive effects on some physical parameters (balance, flexibility, strength, hand-eye coordination) and social skills (matching skills, imitation skills, following instructions skills, visual support use, receptive language skills, communicative language skills, game and music skills, selfcare skills, daily life skills, motor skills, socialization skills, and mathematics).
\end{abstract}

Keywords: Autism, Educational game, Social skills, Training.

Citation | Nurgül TEZCAN KARDAŞ; Reşat SADIK (2018). An Analysis of the Effect of Educational Game Training on Some Physical Parameters and Social Skills of the Children with Autism Spectrum Disorders. Asian Journal of Education and Training, 4(4): 319-325.

History:

Received: 30 May 2018

Revised: 2 August 2018

Accepted: 6 September 2018

Published: 24 September 2018

Licensed: This work is licensed under a Creative Commons Attribution 3.0 License $(\mathrm{cc})$

Publisher:Asian Online Journal Publishing Group
Contribution/Acknowledgement: Both authors contributed to the conception and design of the study.

Funding: This study received no specific financial support.

Competing Interests: The authors declare that they have no conflict of interests.

Transparency: The authors confirm that the manuscript is an honest, accurate, and transparent account of the study was reported; that no vital features of the study have been omitted; and that any discrepancies from the study as planned have been explained.

Ethical: This study follows all ethical practices during writing.

\section{Contents}

1. Introduction 290

2. Material Method 320

3. Findings 321

4. Discussion and Conclusion. 324

References 


\section{Introduction}

As it is known, autism, widespread and on the rise today, is one of the diseases that are caused by the failure of the different parts of the brain in working together. The word autism is made up of the Greek word "autos" (itself) and the Latin "ismus" (a suffix indicating belief in, practice of, condition of, or process). For the first time in 1908, Eugen Bleuler saw "autism" as a serious symptom of schizophrenic patients and described it as "an unhealthy selflove and withdrawal" (Gillberg and Coleman, 2000). In general, autism is defined as a pervasive developmental disorder, in which verbal and nonverbal communication, social interaction, imagination and problem solving abilities are impaired. In the literature, autism is referred to as autism spectrum disorder (ASD) (Worden and Moore, 2004). ASD is a heterogeneous neuropsychiatric disorder characterized by the impairment, at different levels, in social functions, problems in the areas of communication and behavior, and delays in cognitive development (American Psychiatric Association, 2013). Children with ASD experience difficulties in social relations, and these children do not seek attachment. Children with ASD are content with being alone; they do not speak for attracting attention, do not care for their families, rarely establish eye contact, do not gesture or try to draw the attention of others. These children have problems in communication skills, and most of them do not only not speak but do not use non-verbal methods of communication either (Nicholas et al., 2008).

Cognitive, emotional and psychomotor development of children with ASD is very important. Studies in the field show that physical education, sports and educational games are extremely effective for the development of autistic children. Physical education and sports help individuals to overcome their problems and get a chance to have meaningful lives by minimizing their feelings of loneliness. Physical education and sports activities to be utilized in the education of autistic children help to improve not only their motor skills but also their physical and motor fitness, game skills, positive self-perception, social competence, free time skills, ease tension and help to improve their creative expressions (Calışkan, 2011). Development of basic motor skills in autistic children is important not only for influencing their development in different aspects but also for ensuring their happiness. Development of movement skills in autistic children is also important for their learning more complex behaviors. Development of these skills helps prepare a ground for other bodily movements and achieve complex movements, and provides emotional and social benefits by means of movement training (Sarol et al., 2011). As they bring about provably and observably positive changes in autistic children, sports activities have become more preferred in relieving autism and its associated effects (Karaküçük, 2012). Yılmaz (2004) found that children diagnosed with autism generally have poor motor skills; and therefore, Yllmaz argued that the sports training programs designed for children with ASD must focus on developmental activities containing individual games and sports that will improve basic motor skills and enhance physical activity (Yilmaz, 2004). Shaped by the information drawn from literature on the field, this research aims to measure the effect of educational game training on some physical parameters and social skills of children with Autism Spectrum Disorders.

\section{Material Method}

\subsection{Research Method}

This study is designed in accordance with relational screening model, as it looks into the physical and social effects of the educational games on children with Autism Spectrum Disorder.

\subsection{Study Group}

Study group of the research consists of 5 male students within the age range of 5 to 8 , officially diagnosed with Autism Spectrum Disorder (ASD) and with degrees of disability close to each other. Participants receive training at “Özel İzle Otizm Spor Kulübü” in Düzce province (a special sports club for the autistic), affiliated with the Ministry of National Education.

\subsection{Data Collection Tools and Data Collection Process}

Data within the scope of the research have been collected by means of the measurement tools, the protocols of which are given.

a) To determine the level of the performance of social skills, "Performance Evaluation Form for Individuals with Pervasive Developmental Disorder" was used. Developed within the scope of the "Support Training Program for Prevalent Developmental Disorders" and by the Ministry of National Education, General Directorate of Special Education and Rehabilitation Services, the said form is a standard measure used as a performance measurement instrument in all rehabilitation centers throughout the country."Support Training Program for Prevalent Developmental Disorders," which uses the said form as a standard measurement tool, has been prepared with a view to enable the individuals with prevalent developmental disorders, attending the special education and rehabilitation centers within the scope of special education services, to benefit from the training settings efficiently and effectively. Additional clause 3 of the law numbered 3797 concerning the Organization and Functions of the Ministry of National Education, and article 25 of the law, dated 24/07/2008 and numbered 5793, concerning Amendments in Some Laws and Decree Laws provide the basis for preparing this program (Ministry of National Education, 2018). "Performance Evaluation Form for Individuals with Prevalent Developmental Disorders" is used for assessing the performance of the individuals in need of special education in terms of their preparation for cognitive skills, self-care skills, daily life skills, social life skills, language and alternative communication skills, pyscho-motor skills, social life skills, Turkish language and mathematical skills and preparing an education plan accordingly.

b) In determining the physical parameters, various motor tests (flamingo test, sit and reach test, vertical jump test, plate tapping test) were used.

\subsubsection{Physical Test Protocols}

Flamingo Balance Test: In order to determine the static balance of the subjects in the research group, Flamingo Balance Test was used. According to this test, a subjects of the Research group step on a wooden balance 
beam, 50 centimeters long, 4 centimeters high, and 3 centimeters wide, and stand in balance. Bending their other legs and pulling them to their buttocks, they hold them with their hands on the same side. While the research group subjects are thus standing in balance on single foot, the timer is started and they try to stay in balance in this position for 1 minute. When the balance is lost (either by falling off the beam, or by letting go of the foot being held, or by touching the ground with any part of the body, and the like), then the timer is stopped. When the time is up, each attempt at re-gaining balance (after the fall) is counted, and this number is noted as the score of the research group after one minute period is completed (Hazar and Taşmektepligil, 2008).

Sit and Reach Test: Sit and Reach test is used for determining the flexibility of the subjects in the research group. The top of a coffee table, 32 centimeters high and 35 centimeters long, is marked in centimeters. Subjects in the research group sit on the floor, extend their legs and place their feet (shoes off) with the soles flat against the coffee table. Then, without bending knees, and from the trunk (waist and hips), they extend their arms forward on the coffee table as far as possible. The farthest point reached by fingers are recorded in centimeters. The research group repeats this three times and the best score is taken (Hazar and Taşmektepligil, 2008).

Vertical Jump Test: In vertical jumps test, the subjects try jump with both feet as high as possible in front of a platform hung on wall. Before the test, normal arm length of the subject is measured before the test platform. After the test, the difference between the jump height and the arm length is recorded in centimeters. Subjects repeat the test twice and the best score is taken (Ayan and Mülazimoğlu, 2009).

Plate Tapping Test: Plate tapping test is a reliable and effective test to evaluate the coordination and the speed of the limb movement (Adam et al., 1988). Purpose is to quickly touch the two discs one after another with the preferred hand. Two rubber discs $(20 \mathrm{cms}$. in diameter) are fastened on a table of adjustable height. The distance between the two discs from the center must be $80 \mathrm{cms}$. (borders $60 \mathrm{cms}$.). Rectangular plate (10X20 in size) is placed in equal distance from the two discs. The subject stands in front of the table with legs comfortably apart. Non-preferred hand (non-dominant hand) is placed on the plate. The preferred hand (dominant hand) is placed, by moving over the other hand crosswise, on the disc opposite to the preferred hand. The preferred hand placed on the disc is moved back and forth over the other hand to touch the discs as quickly as possible. The test is repeated two times with a 5 minute break in between, and the best time measured with a timer is recorded as the test result. The best result taken in both attempts is recorded as the test score. Score is the time used for touching each disc 25 times and is recorded as the decimal of a second (Telles et al., 2013).

During the data collection process, the participants were administered 8 different games for 8 weeks, 3 days a week, and 1 hour a day. In establishing the educational game program, 3 experts were consulted for their opinions; and the purpose was the improvement in some physical characteristics after the completion of the program. The form used for assessing the performance in social skills was evaluated for each participant and separately by parents, physical education teacher, and special education teacher. The data were obtained at the beginning of the educational game program and the end of the 8 week process and by using the measuring tools, the protocols of which are provided.

\subsection{Analysis of the Data}

In the study, SPSS 25.0 version was used for statistical analyses and the level of significance was set at $\mathrm{P}<0.05$. In analyzing the data obtained, non-parametric Wilcoxon test was used.

\section{Findings}

This section of the study presents the findings obtained by the statistical analyses.

Table-1. Analysis of Some Physical Parameters

\begin{tabular}{|c|c|c|c|c|c|}
\hline & Test & $\mathbf{N}$ & $\bar{x}$ & Sd & $\mathbf{P}$ \\
\hline \multirow{2}{*}{ Vertical Jump } & Post & 5 & 13,00 & 3,47 & \multirow{2}{*}{,039* } \\
\hline & Pre & 5 & 5,00 & 2,34 & \\
\hline \multirow{2}{*}{ Sit and Reach } & Post & 5 & 24,40 & 4,03 & \multirow{2}{*}{,039* } \\
\hline & Pre & 5 & 16,40 & 4,39 & \\
\hline \multirow{2}{*}{ Plate Tapping } & Post & 5 & 9,69 & 3,08 & \multirow{2}{*}{,043* } \\
\hline & Pre & 5 & 17,67 & 7,91 & \\
\hline \multirow{2}{*}{ Flamingo } & Post & 5 & 10,80 & 1,30 & \multirow{2}{*}{, $042^{*}$} \\
\hline & Pre & 5 & $15, \mathrm{OO}$ & 0,00 & \\
\hline
\end{tabular}

According to Table 1, in the analysis of the physical parameters, significant differences are seen in favor of the post-tests in the results of vertical jump $(13,00 \pm 3,47)$, sit and reach $(24,40 \pm 4,03)$, plate tapping $(9,69 \pm 3,08)$, and flamingo tests $(10,80 \pm 1,30)$. 
Table-2. Analysis of Performance Evaluation Test for Individuals with Prevalent Developmental Disorder, in Accordance with the General Averages of Opininons by Three Experts

\begin{tabular}{|c|c|c|c|c|c|}
\hline & Test & $\mathbf{N}$ & $\boldsymbol{X}$ & Sd & $\mathbf{P}$ \\
\hline \multirow{2}{*}{ Matching } & Post & 5 & 1,70 & 0,23 & \multirow{2}{*}{, $001^{*}$} \\
\hline & Pre & 5 & 1,03 & 0,12 & \\
\hline \multirow{2}{*}{ Imitation } & Post & 5 & 1,75 & 0,27 & \multirow{2}{*}{, $001^{*}$} \\
\hline & Pre & 5 & 1,07 & 0,16 & \\
\hline \multirow{2}{*}{ Following Instructions } & Post & 5 & 1,74 & 0,31 & \multirow{2}{*}{, $001 *$} \\
\hline & Pre & 5 & 1,02 & 0,11 & \\
\hline \multirow{2}{*}{ Visual Support } & Post & 5 & 1,52 & 0,46 & \multirow{2}{*}{, $027 *$} \\
\hline & Pre & 5 & 1,21 & 0,41 & \\
\hline \multirow{2}{*}{ Receptive Language Skills } & Post & 5 & 1,67 & 0,16 & \multirow{2}{*}{, $001^{*}$} \\
\hline & Pre & 5 & 1,07 & 0,15 & \\
\hline \multirow{2}{*}{ Communicative Language } & Post & 5 & 1,87 & 0,19 & \multirow{2}{*}{, $001 *$} \\
\hline & Pre & 5 & 1,47 & 0,43 & \\
\hline \multirow{2}{*}{ Game and Music } & Post & 5 & 1,71 & 0,28 & \multirow{2}{*}{, $001^{*}$} \\
\hline & Pre & 5 & 1,26 & 0,29 & \\
\hline \multirow{2}{*}{ Self-care } & Post & 5 & 1,56 & 0,29 & \multirow{2}{*}{, $001 *$} \\
\hline & Pre & 5 & 1,06 & 0,12 & \\
\hline \multirow{2}{*}{ Daily Life } & Post & 5 & 1,86 & 0,16 & \multirow{2}{*}{, $\mathrm{OO} 1^{*}$} \\
\hline & Pre & 5 & 1,55 & 0,21 & \\
\hline \multirow{2}{*}{ Motor Skills } & Post & 5 & 1,74 & 0,11 & \multirow{2}{*}{, $\mathrm{OO} 1^{*}$} \\
\hline & Pre & 5 & 1,07 & 0,07 & \\
\hline \multirow{2}{*}{ Social Skills } & Post & 5 & 1,89 & 0,08 & \multirow{2}{*}{, $\mathrm{OO} 1^{*}$} \\
\hline & Pre & 5 & 1,44 & 0,26 & \\
\hline \multirow{2}{*}{ Mathematics } & Post & 5 & 1,93 & 0,11 & \multirow{2}{*}{, $\mathrm{OO} 1^{*}$} \\
\hline & Pre & 5 & 1,22 & 0,15 & \\
\hline
\end{tabular}

When the Table 2, "Performance Evaluation Test for Individuals with Prevalent Developmental Disorder, in Accordance with the General Averages of Opininons by Three Experts", is analyzed and the $p$ values $(p<0,05)$ of the sub-dimensions are considered, significant differences are found in favor of the post tests in the results of matching skills $(1,70 \pm 0,23)$, imitation skills $(1,75 \pm 0,27)$, instruction following skills $(1,74 \pm 0,31)$, using visual support $(1,52 \pm 0,46)$, receptive language skills $(1,67 \pm 0,16)$, communicative language skills $(1,87 \pm 0,19)$, game and music skills $(1,71 \pm 0,28)$, self-care skills $(1,56 \pm 0,29)$, daily life skills $(1,86 \pm 0,16)$, motor skills $(1,74 \pm 0,11)$, social skills $(1,89 \pm 0,08)$ and mathematics $(1,93 \pm 0,11)$.

Table-3. Analysis of Performance Evaluation Test for Individuals with Prevalent Developmental Disorder, According to the Family

\begin{tabular}{|c|c|c|c|c|c|}
\hline & Test & $\mathbf{N}$ & $\overline{\boldsymbol{X}}$ & Sd & $\mathbf{P}$ \\
\hline \multirow{2}{*}{ Matching } & Post & 5 & 1,74 & 0,28 & \multirow{2}{*}{, $042^{*}$} \\
\hline & Pre & 5 & 1,00 & 0,00 & \\
\hline \multirow{2}{*}{ Imitation } & Post & 5 & 1,76 & 0,35 & \multirow{2}{*}{, $043 *$} \\
\hline & Pre & 5 & 1,05 & 0,55 & \\
\hline \multirow{2}{*}{ Instructions } & Post & 5 & 1,75 & 0,35 & \multirow{2}{*}{,039* } \\
\hline & Pre & 5 & 1,00 & 0,00 & \\
\hline \multirow{2}{*}{ Visual Support } & Post & 5 & 1,43 & 0,51 & \multirow{2}{*}{, 194} \\
\hline & Pre & 5 & 1,03 & 0,08 & \\
\hline \multirow{2}{*}{ Receptive Language } & Post & 5 & 1,66 & 0,17 & \multirow{2}{*}{, $041^{*}$} \\
\hline & Pre & 5 & 1,01 & 0,03 & \\
\hline \multirow{2}{*}{ Communicative Language } & Post & 5 & 1,86 & 0,23 & \multirow{2}{*}{, $042^{*}$} \\
\hline & Pre & 5 & 1,45 & 0,43 & \\
\hline \multirow{2}{*}{ Game and Music } & Post & 5 & 1,71 & 0,30 & \multirow{2}{*}{, $043^{*}$} \\
\hline & Pre & 5 & 1,24 & 0,28 & \\
\hline \multirow{2}{*}{ Self-care } & Post & 5 & 1,59 & 0,30 & \multirow{2}{*}{, $042^{*}$} \\
\hline & Pre & 5 & 1,03 & 0,05 & \\
\hline \multirow{2}{*}{ Daily Life } & Post & 5 & 1,90 & 0,17 & \multirow{2}{*}{,039* } \\
\hline & Pre & 5 & 1,51 & 0,22 & \\
\hline \multirow{2}{*}{ Motor } & Post & 5 & 1,76 & 0,12 & \multirow{2}{*}{, $042^{*}$} \\
\hline & Pre & 5 & 1,09 & 0,09 & \\
\hline \multirow{2}{*}{ Social Skills } & Post & 5 & 1,92 & 0,07 & \multirow{2}{*}{, $042^{*}$} \\
\hline & Pre & 5 & 1,45 & 0,26 & \\
\hline \multirow{2}{*}{ Mathematics } & Post & 5 & 1,97 & 0,05 & \multirow{2}{*}{, $043^{*}$} \\
\hline & Pre & 5 & 1,25 & 0,15 & \\
\hline
\end{tabular}

When the Table 3, "Performance Evaluation Test for Individuals with Prevalent Developmental Disorder, According to the Family" is analyzed and the $\mathrm{p}$ values $(\mathrm{p}<0,05)$ of the sub-dimensions are considered, significant differences are found in favor of the post tests in the results of matching skills $(1,74 \pm 0,28)$, imitation skills $(1,76 \pm$ $0,35)$, instruction following skills $(1,75 \pm 0,35)$, receptive language skills $(1,66 \pm 0,17)$, communicative language skills $(1,86 \pm 0,23)$, game and music skills $(1,71 \pm 0,30)$, self-care skills $(1,59 \pm 0,30)$, daily life skills $(1,90 \pm 0,17)$, motor skills $(1,76 \pm 0,12)$, social skills $(1,92 \pm 0,07)$ and mathematics $(1,97 \pm 0,05)$. No significant difference is found in the sub-dimension of using visual support $(\mathrm{p}=0,194)$. 
Table-4. Analysis of Performance Evaluation Test for Individuals with Prevalent Developmental Disorder, According to PE and Sports Teacher

\begin{tabular}{|c|c|c|c|c|c|}
\hline & Test & $\mathbf{N}$ & $\overline{\bar{x}}$ & Sd & $\mathbf{P}$ \\
\hline \multirow{2}{*}{ Matching } & Post & 5 & 1,60 & 0,25 & \multirow{2}{*}{, $042^{*}$} \\
\hline & Pre & 5 & 1,00 & 0,00 & \\
\hline \multirow{2}{*}{ Imitation } & Post & 5 & 1,69 & 0,33 & \multirow{2}{*}{, $042^{*}$} \\
\hline & Pre & 5 & 1,01 & 0,02 & \\
\hline \multirow{2}{*}{ Instructions } & Post & 5 & 1,75 & 0,32 & \multirow{2}{*}{, $042^{*}$} \\
\hline & Pre & 5 & 1,00 & 0,00 & \\
\hline \multirow{2}{*}{ Visual Support } & Post & 5 & 1,60 & 0,47 & \multirow{2}{*}{, 109} \\
\hline & Pre & 5 & 1,20 & 0,44 & \\
\hline \multirow{2}{*}{ Receptive Language } & Post & 5 & 1,68 & 0,17 & \multirow{2}{*}{, $042^{*}$} \\
\hline & Pre & 5 & 1,06 & 0,09 & \\
\hline \multirow{2}{*}{ Communicative Language } & Post & 5 & 1,86 & 0,23 & \multirow{2}{*}{, $042^{*}$} \\
\hline & Pre & 5 & 1,46 & 0,45 & \\
\hline \multirow{2}{*}{ Game and Music } & Post & 5 & 1,72 & 0,30 & \multirow{2}{*}{, $043^{*}$} \\
\hline & Pre & 5 & 1,27 & 0,32 & \\
\hline \multirow{2}{*}{ Self-care } & Post & 5 & 1,54 & 0,26 & \multirow{2}{*}{$043^{*}$} \\
\hline & Pre & 5 & 1,03 & 0,05 & \\
\hline \multirow{2}{*}{ Daily Life } & Post & 5 & 1,88 & 0,16 & \multirow{2}{*}{, $042^{*}$} \\
\hline & Pre & 5 & 1,55 & 0,23 & \\
\hline \multirow{2}{*}{ Motor } & Post & 5 & 1,75 & 0,11 & \multirow{2}{*}{, $041^{*}$} \\
\hline & Pre & 5 & 1,07 & 0,07 & \\
\hline \multirow{2}{*}{ Social Skills } & Post & 5 & 1,87 & 0,09 & \multirow{2}{*}{, $042^{*}$} \\
\hline & Pre & 5 & 1,40 & 0,28 & \\
\hline \multirow{2}{*}{ Mathematics } & Son & 5 & 1,91 & 0,13 & \multirow{2}{*}{, $042^{*}$} \\
\hline & Ön & 5 & 1,17 & 0,16 & \\
\hline
\end{tabular}

$$
{ }^{*} \mathrm{p}<.05
$$

When the Table 4, "Performance Evaluation Test for Individuals with Prevalent Developmental Disorder, According to PE and Sports Teacher" is analyzed and the p values $(\mathrm{p}<0,05)$ of the sub-dimensions are considered, significant differences are found in favor of the post tests in the results of matching skills $(1,69 \pm 0,33)$, imitation skills $(1,69 \pm 0,33)$, instruction following skills $(1,75 \pm 0,32)$, receptive language skills $(1,68 \pm 0,17)$, communicative language skills $(1,86 \pm 0,23)$, game and music skills $(1,72 \pm 0,30)$, self-care skills $(1,54 \pm 0,26)$, daily life skills $(1,88$ $\pm 0,16)$, motor skills $(1,75 \pm 0,11)$, social skills $(1,87 \pm 0,09)$ and mathematics $(1,87 \pm 0,09)$. No significant difference is found in the sub-dimension of using visual support $(\mathrm{p}=0,109)$.

When the Table 5, "Performance Evaluation Test for Individuals with Prevalent Developmental Disorder, According to Special Education Teacher" is analyzed and the $p$ values $(p<0,05)$ of the sub-dimensions are considered, significant differences are found in favor of the post tests in the results of matching skills $(1,76 \pm 0,18)$, imitation skills $(1,80 \pm 0,15)$, instruction following skills $(1,71 \pm 0,32)$, receptive language skills $(1,66 \pm 0,19)$, game and music skills $(1,71 \pm 0,20)$, self-care skills $(1,54 \pm 0,37)$, motor skills $(1,70 \pm 0,11)$, social skills $(1,88 \pm 0,08)$, and mathematics $(1,91 \pm 0,13)$. No significant difference was found in the sub-dimensions of using visual support $(\mathrm{p}=0,655)$, communicative language skills $(\mathrm{p}=068)$, daily life skills $(\mathrm{p}=0,138)$.

Table-5. Analysis of Performance Evaluation Test for Individuals with Prevalent Developmental Disorder, According to Special Education Teacher

\begin{tabular}{|c|c|c|c|c|c|}
\hline & Test & $\mathbf{N}$ & $\bar{x}$ & Sd & $\mathbf{P}$ \\
\hline \multirow{2}{*}{ Matching } & Post & 5 & 1,76 & 0,18 & \multirow{2}{*}{, $042^{*}$} \\
\hline & Pre & 5 & 1,10 & 0,22 & \\
\hline \multirow{2}{*}{ Imitation } & Post & 5 & 1,80 & 0,15 & \multirow{2}{*}{,039* } \\
\hline & Pre & 5 & 1,14 & 0,29 & \\
\hline \multirow{2}{*}{ Instructions } & Post & 5 & 1,71 & 0,32 & \multirow{2}{*}{, $042^{*}$} \\
\hline & Pre & 5 & 1,08 & 0,19 & \\
\hline \multirow{2}{*}{ Visual Support } & Post & 5 & 1,54 & 0,50 & \multirow{2}{*}{, 665} \\
\hline & Pre & 5 & 1,40 & 0,54 & \\
\hline \multirow{2}{*}{ Receptive Language } & Post & 5 & 1,66 & 0,19 & \multirow{2}{*}{, $042^{*}$} \\
\hline & Pre & 5 & 1,15 & 0,25 & \\
\hline \multirow{2}{*}{ Communicative Language } & Post & 5 & 1,90 & 0,21 & \multirow{2}{*}{,068 } \\
\hline & Pre & 5 & 1,53 & 0,49 & \\
\hline \multirow{2}{*}{ Game and Music } & Post & 5 & 1,71 & 0,20 & \multirow{2}{*}{,043* } \\
\hline & Pre & 5 & 1,28 & 0,32 & \\
\hline \multirow{2}{*}{ Self-care } & Post & 5 & 1,54 & 0,37 & \multirow{2}{*}{, $043^{*}$} \\
\hline & Pre & 5 & 1,11 & 0,19 & \\
\hline \multirow{2}{*}{ Daily Life } & Post & 5 & 1,80 & 0,18 & \multirow{2}{*}{, 138} \\
\hline & Pre & 5 & 1,60 & 0,22 & \\
\hline \multirow{2}{*}{ Motor } & Post & 5 & 1,70 & 0,11 & \multirow{2}{*}{, $043^{*}$} \\
\hline & Pre & 5 & 1,06 & 0,07 & \\
\hline \multirow{2}{*}{ Social Skills } & Post & 5 & 1,88 & 0,08 & \multirow{2}{*}{, $043^{*}$} \\
\hline & Pre & 5 & 1,48 & 0,29 & \\
\hline \multirow{2}{*}{ Mathematics } & Post & 5 & 1,91 & 0,13 & \multirow{2}{*}{, $043^{*}$} \\
\hline & Pre & 5 & 1,26 & 0,16 & \\
\hline
\end{tabular}




\section{Discussion and Conclusion}

Aiming to measure the effects of educational game training on some physical parameters and social skills of the children with Autism Spectrum Disorder, this study determined not only some physical parameters obtained from the children participating in the study (flexibility, balance, strength, and coordination), but also tested, through tests mentioned, their mapping skills, imitation skills, instruction following skills, visual support use skills, receptive and communicative language skills, game and music skills, self-care skills, daily life skills, motor skills, social skills and mathematical knowledge. In the study conducted, it was concluded that 8 -week educational game program brought about a multi-dimensional improvement in the autistic children participating in the study as well as a decrease in their problematic behaviours.

In the literature, there is much research on the effects of physical education and sports on the general development of the mentally challenged children, and these studies point out that exercise activities used in the rehabilitation of the autistic children contribute to the rehabilitation and multi-dimensional development (mental, emotional, social, psychological, characteristic and motor skills) of these children (Atalay and Karadağ, 2011).

In a study conducted at Georgia State University, Mays (2013) stated that as a result of the aerobic exercises administered to two autistic children, there was a decrease in their short term stereotypical behaviors (Mays, 2013). In a study conducted by Orhan (2014) a 10-year-old boy with autism, who had not had movement training, performed a 30-minute work consisting of 12 exercises, double-leg multiple forward bounces, multiple forward bounces on single leg (left and right legs), and multiple forward bounces in zigzags. As a result of the movement training, it was found that there was a decrease in the problematic behaviors of the child, as well as an increase in his participation duration in the activity and his self-confidence (Orhan, 2014). On the other hand, Yanardağ (2007) applied Bruininks-Oseretsky Test of Motor Proficiency on 8 autistic boys aged between 5 and 7 for 12 weeks, 3 days a week, and 40 minutes a day, both in and out of the swimming pool. In this study, it was found that the land group moved from a pre-test score of 0.75 to 1.75 in balance test (Yanardağ, 2007).

Furthermore, it is seen that the social skills of the autistic children participating in the study have also improved. As it is known, sports help the disabled in terms of their psychological and social development, and facilitate their socialization (Eichsteadt and Lavay, 1992). For this reason, sports should be considered as a means to implement the socialization of the disabled and accelerate this process (Dunn and Fait, 1997). When the literature in the field is examined, one can find studies about the positive effects of the exercise programs of various forms on the levels of the social adaptation of the disabled.

Study conducted by Temel et al. (2017) corroborates this view. In the said study, it was found that the level of aggressiveness in the autistic children who are engaged in sports is lower than that of the autistic children who are not engaged in sports, and that the level of social adaptation of the former is also higher than that of the latter (Temel et al., 2017). Another study looked into the effects of the intensive exercises on the problematic behaviors, in an exercise program of 6 weeks, 4 days a week, and 2 hours a day. This study was done with an 8 -year-old autistic individual. As a result of the exercises designed in the game format, a decrease was observed in the problematic behaviors (Beyazoğlu, 2014). In a study on the effects of the basketball training on the behavioral development of the mentally challenged children, Gençöz (1997) has found positive changes in the behavior of these children both in the family and school environments (Gençöz, 1997). Another study finds positive changes in the level of socialization of an autistic individual after movement training, especially positive results at the levels of establishing eye contact (Orhan, 2014). The changes, found by this study, at the levels of socialization of the autistic children also corroborate the findings in the literature. In a study, Mcmahon has argued for the importance of recreational activities in establishing the socialization of the disabled individuals, their adaptation to the environment, their making friends and social acceptance (Mcmahon, 1998).

Findings from the related studies in the literature are in parallel with this study. Considering the results of this study, it can be said that the educational game program applied to the children with prevalent spectrum disorder have positive impacts on some of the physical and social skills. Using some sports exercises and educational games in the training of the individuals with ASD will support the adaptation of these individuals to social life, and thus, is thought to be contributing to their socialization. Accordingly, structured educational game programs can be integrated into the existing educational programs of the rehabilitation centers and a new program to support the rehabilitation of the individuals with ASD can be formed.

\section{References}

Adam, C., V. Klissouras, M. Ravazzolo, R. Renson and W. Tuxworth, 1988. Eurofit: European test of physical fitness. Rome, Italy: Council of Europe, Committee for the Development of Sport.

American Psychiatric Association, 2013. Diagnostic and statistical manual of mental disorders. 5th Edn., Washington, DC: American Psychiatric Association. pp: 50-59.

Atalay, A. and A. Karadağ, 2011. Importance of sports therapies in the rehabilitation process of the autistic patients; selçuk university. Journal of Physical Education and Sports, 13(Extra Issue): 227.

Ayan, V. and O. Mülazimoğlu, 2009. An analysis of the physical characteristics and some performance profiles of 8-10 age group male children in sporda talent selection and sports orientation (Ankara Example). FÜ Right. Know. Medical Journal, 23(3): 113-1 18.

Beyazoğlu, G., 2014. Examination of the effects of play and water therapy on behavioral disorder reduction in a child with autism diagnosis. Karadeniz Technical University Educational Sciences Institute, Graduate Thesis, Trabzon. [Analysis of the Effects of Game and Water Therapies in Alleviating the Behavioral Disorders in a Child Diagnosed with Autism, Master's Thesis].

Calışkan, E., 2011. Sports education for children with disabilities and approaches to their families. 1. Book of Physical Education and Sports Congress in Internationally Disabled Persons. Selcuk University School of Physical Education and Sports. Konya.

Dunn, J.M. and H. Fait, 1997. Special physical education: Adapted, individualized. Developmental 7th Edn., Benchmark: Lowa Dubuqua Brown, 22 .

Eichsteadt, C.B. and B.W. Lavay, 1992. Physical activity for individuals with mental retardation: Infancy through adulthood. Champaign, IL: Human Kinetics. pp: 389-390.

Gençöz, F., 1997. The effects of basketball training on the maladaptive behaviors of trainable mentally retarded children. Research in Developmental Disabilities, 18(1): 1-10.Available at: https://doi.org/10.1016/s0891-4222(96)00029-7.

Gillberg, C. and M. Coleman, 2000. The biology of the autistic syndromes. London, New York: Mac Keith Press, Distributed By Cambridge University Press. 
Hazar, F. and Y. Taşmektepligil, 2008. Investigation of the effects of balance and flexibility on agility in the pre-puberty period. Spormetre: Physical Education and Sports Sciences Journal, 6(1): 9-12.

Karaküçük, S., 2012. Therapeutic recreation. 1st Edn., Ankara: Gazi Bookstore.

Mays, M.N.M., 2013. Using antecedent aerobic exercise to decrease stereotypic behavior in children with autism. Dissertation, Georgia State University.

Mcmahon, D., J., 1998. Social acceptance of children with developmental handicaps İnintegrated daycamps. Canada: University of Toronto.

Ministry of National Education, 2018. Available from https://orgm.meb.gov.tr/meb_iys_dosyalar/2013_09/04010347_yaygngeliimselbozukluklardestekeitimprogram.pdf [Accessed $02.07 .2018]$.

Nicholas, J.S., J.M. Charles, L.A. Carpenter, L.B. King, W. Jenner and E.G. Spratt, 2008. Prevalence and characteristics of children with autism-spectrum disorders. Annals of Epidemiology, 18(2): 130-136.

Orhan, B.E., 2014. Impact of movement education on social skills in autism. Graduate Thesis, Gazi University Institute of Educational Sciences, Ankara. [Effects of Movement Training on Social Skills in Autism, Master's Thesis].

Sarol, H., E. Ekinci and S. Karaküçük, 2011. Opinions of the students of the physical education and sports high school participating voluntarily in the autistic children's sport training project. Selçuk University Physical Education and Soprts Sciences Journal, 13(Extra Issue): 67-73.

Telles, S., N. Singh, A.K. Bhardwaj, A. Kumar and A. Balkrishna, 2013. Effect of yoga or physical exercise on physical, cognitive and emotional measures İn children: A randomized controlled trial. Child and Adolescent Psychiatry and Mental Health, 7(1): 37.Available at: https://doi.org/10.1186/1753-2000-7-37.

Temel, G., T. Yıldız, M. Turan and B. Karaoğlu, 2017. Analysis of the effect of sports on the levels of aggressiveness and social adaptation of the autistic children. Istanbul University Sports Sciences Journal, 7(3): 25-33.

Worden, E.C. and K.A. Moore, 2004. Sensory gardens. University of Florida Cooperative Extension Service, Institute of Food and Agricultural Sciences. pp: 1-4.

Yanarda $\breve{g}$, M., 2007. Effects of different exercise practices on motor performance and stereotypic behavior in autistic children. Hacettepe University Institute of Health Sciences, PhD Thesis, Ankara.

Yllmaz, A., 2004. Family education, Bursa Province directorate of national education. Independent Autistic Children Education Center, Family Education Symposium. 